\title{
The Effect of Time and of Vasoactive Drugs on Capillary Leakage Induced During Myocardial Contrast Echocardiography
}

\author{
Douglas Miller, Ph.D., ${ }^{*}$ Peng Li, M.D., Ph.D. $\dagger$ and William F. Armstrong, M.D. $\dagger$ \\ *Department of Radiology, University of Michigan, $\dagger$ Department of Cardiology, \\ University of Michigan, Ann Arbor, Michigan
}

Background: Premature ventricular contractions (PVC), capillary leakage, and petechial hemorrhage can occur during myocardial contrast echocardiography (MCE). The effects occur as a result of the interaction of contrast agent microbubbles and the ultrasound, but the detailed etiology of the effects is not yet clear. This study tested the hypothesis that the capillary leakage results from a physiological response to injury, which might be protracted and modulated by vasoactive drugs. Methods: Hairless rats were anesthetized and transthoracically scanned with a diagnostic ultrasound system (GE Vingmed System V) at 1.7 MHz with 1:4 triggered frames at end systole. The scan head and rats were mounted in a $37^{\circ} \mathrm{C}$ water bath to assure free-field conditions and placement of the heart at a similar focal distance as humans. A tail vein was cannulated for injections of Optison ${ }^{\circledR}$ contrast agent, vasoactive medications, and Evans Blue dye (EB). EB was injected as a marker of capillary leakage before or after scanning. Results: PVCs, petechia, and capillary leakage occurred during ultrasound exposure of microbubbles in myocardium, with no effects detected in shams. The influence of the vasoactive medications propranolol and isoproterenol on the effects did not support the hypothesis. Capillary leakage occurred during and postexposure, but diminished for EB injection 20 minutes after scanning with or without isoproterenol pretreatment. Conclusion: MCE induced PVCs, petechia, and capillary leakage, all of which ended immediately or within 20 minutes after the examination. Contrary to the hypothesis of a physiological mechanism, the capillary leakage appears to be primarily a mechanical effect rather than a physiological response. (ECHOCARDIOGRAPHY, Volume 21, February 2004)

ultrasound contrast agent, Optison ${ }^{\circledR}$, capillary leakage, petechiae, acoustic cavitation, premature ventricular contraction

Ultrasound contrast agents for use in myocardial contrast echocardiography (MCE) are based on stabilized gas bodies, which provide highly echogenic microbubbles for imaging. These agents appear to be safe and efficacious within the Food and Drug Administration approval process and in widespread clinical usage. ${ }^{1}$ One reservation with regard to safety is the acoustic cavitation-like interaction of ultrasound pulses with the gas bodies, which is a well-known intermediary of microscale bioeffects. ${ }^{2}$ Bioeffects specifically related to ultrasound contrast agents have been the subject of several recent reviews. ${ }^{3-5}$ Initially, petechial hemorrhages were noted from diagnostic ultrasound scanning of skeletal mus-

Address for correspondence and reprint requests: Douglas Miller, Ph.D., 3315 Kresge III, University of Michigan Medical Center, 200 Zina Pitcher Place, Ann Arbor, MI 481090553. Fax: (734)764-8541; E-mail: douglm@umich.edu cle with contrast agent in the circulation. ${ }^{6-8}$ More recently, research on MCE has led to reports of premature ventricular contractions (PVCs) in humans, ${ }^{9}$ ruptured capillaries in isolated rabbit hearts, ${ }^{10}$ troponin T-elevation after rat heart scanning, ${ }^{11}$ and capillary leakage together with PVCs and petechiae in rat hearts. ${ }^{12}$ Relatively high-pressure amplitude pulsed ultrasound exposure of rat hearts with contrast agents causes arrhythmias and histologically defined myocardial degeneration. ${ }^{13}$ Acoustic emissions from cavitation activity have been detected during MCE. ${ }^{14}$ All of these effects clearly result from the interaction of ultrasound pulses with the contrast agent microbubbles, but the detailed etiology of the bioeffects is unclear. Specific knowledge of the microscale phenomenon and mechanisms causing these bioeffects would be of value for predicting or avoiding them, and for understanding their clinical implications. 
Although the capillary leakage and petechiae seem to be similar effects, these did not appear to be well correlated. ${ }^{12}$ For example, the petechiae often occurred outside areas colored by Evans blue leakage. The petechiae probably result from the mechanical rupture of capillaries induced as microbubbles expand and collapse during an ultrasound pulse. However, capillary or postcapillary venule permeability can be increased as a physiological response, and might be caused by a different mechanism than the petechiae. Interaction of ultrasound with contrast agents is known to damage cells, including red cells, ${ }^{15,16}$ platelets, ${ }^{17}$ neutrophils, ${ }^{18}$ macrophages ${ }^{19}$ endothelium-like cells,${ }^{19,20}$ and presumably others. Substances released in response to cellular injury, such as platelet activating factor (PAF) and histamine from mast cells, ${ }^{21}$ can cause a localized capillary permeabilization. ${ }^{22}$ Therefore, it seems possible that substances released in localized injury from contrast agent interaction with ultrasound could lead to an increase in capillary permeability after a few minutes within a scanned region of myocardium. This possibility is pressing because a physiological response of this type might be more worrisome than a purely mechanical effect, particularly for patients with cardiovascular disease. The purpose of this study was to test the hypothesis that injuryinduced release of vasoactive substances leads to the capillary leakage associated with MCE by assessing the influence of vasoactive drugs and the time course of the capillary leakage.

\section{Methods}

The methods used for this research have been described previously. ${ }^{12}$ Briefly, CD hairless rats (Charles River Laboratories, Wilmington MA), 7-10 weeks in age and weighing 250$430 \mathrm{~g}$, were anesthetized by an intraperitoneal injection of ketamine $(87 \mathrm{mg} / \mathrm{ml})$ and xylazine $(13 \mathrm{ml} / \mathrm{kg})$. The use of animals in this study was approved by the University of Committee on Use and Care of Animals. A 24G catheter was inserted into a tail vein, and the rat was mounted in a $37^{\circ} \mathrm{C}$ degassed water bath.

Echocardiograms were performed on a commercially available diagnostic ultrasound system (GE Vingmed System V) with a standard cardiac probe (FPA2.5). Ultrasound images of a short axis view of the left ventricle were acquired with each heart located at an image depth of $5 \mathrm{~cm}$. Echocardiograms were triggered from the ECG at $1: 4$ at end-systole. The image settings were $1.7 \mathrm{MHz}$ frequency, $0 \mathrm{~dB}$ power setting, $119 \mathrm{~Hz}$ frame rate, $5 \mathrm{~cm}$ focus, and $10 \mathrm{~cm}$ depth. The peak rarefactional pressure amplitude of the $790 \mathrm{~ns}$ pulses corresponding to $0 \mathrm{~dB}$ was $1.9 \mathrm{MPa}$ in situ, with an equivalent mechanical index of 1.5 , which was measured as described previously. ${ }^{12}$ Sham treatment consisted of echocardiography for 5 minutes followed by injection of the contrast agent with the scan head aimed away from the rat. MCE treatment involved injection of the contrast agent before the 5-minute period of imaging, so that the imaging ultrasound pulses interacted with the microbubbles in the heart. The images obtained during the scanning period were recorded on SVHS videotape for later heart rate determination and counting of PVCs.

The ultrasound contrast media was a commercial ultrasound contrast agent, Optison ${ }^{\circledR}$ (Mallinckrodt Inc., St. Louis, MO). This agent consists of albumin-shelled microbubbles containing perfluoropropane gas, with an average diameter of $3.6 \mu \mathrm{m}$ and concentration of $8 \times 10^{8} / \mathrm{ml}$. A dose of $0.5 \mathrm{ml} / \mathrm{kg}$ was administrated to each rat as a bolus injection with $1 \mathrm{ml}$ saline flush. This relatively high dose, which was about 10 times the recommended human clinical dose, was chosen to reliably elicit clear changes in the measured endpoints in order to afford relatively high sensitivity for the relative comparison tests.

The vasoactive medications used to test for possible modulation of capillary leakage were $10 \mu \mathrm{g} / \mathrm{kg}$ isoproterenol ((-)isoproterenol hydrochloride, Sigma Aldrich Co. St. Louis, MO) IV, or $100 \mu \mathrm{g} / \mathrm{kg}$ propranolol ((S)-(-)propranolol hydrochloride, Sigma Aldrich) IP. The isoproterenol and propranolol were used at dosages known to decrease or to increase, respectively, capillary leakage, which results as a physiological response to substances such as PAF and histamine. ${ }^{23}$ Under the hypothesis, the capillary or postcapillary venule leakage would be expected to be protracted for some time after MCE, since it might be a cascading series of inflammation-like events. The duration of the induced capillary leakage was measured simply by delaying Evans blue injection for various times after MCE.

The study protocol was as follows: real time images were recorded for several cardiac cycles at the very beginning of the procedure. After triggered imaging was activated, an injection of medication was applied while the tape kept on recording for 10 minutes, followed by Optison ${ }^{\circledR}$ administration. The standard MCE 
duration was 5 minutes after the appearance of microbubbles in left ventricular (LV) cavity. Evans Blue (EB) dye at $50 \mathrm{mg} / \mathrm{kg}$ was injected at different times for different groups including 3 minutes prior to Optison ${ }^{\circledR}$ injection, at the end of the standard exposure, 10 minutes after, and 20 minutes after imaging. Rats were euthanized 8 minutes after EB injections, and the circulation was perfused with heparinized saline. The heart was then excised, and flushed through the root of aorta with heparinized saline to clear the cardiac chambers and blood vessels of $\mathrm{EB}$, so that any remaining $\mathrm{EB}$ was present in the interstitium and indicated leakage from effected capillaries. Gross photomicrographs were taken using a stereomicroscope microscope (Leica MZFLIII) fitted with a digital camera. At the same time, the numbers of petechia visible on the anterior and posterior surfaces were counted. The EB leakage area on the anterior surface was measured by image analysis from the gross photographs and expressed as a percentage of the total anterior surface area. A section of the heart about $8 \mathrm{~mm}$ thick and completely including any blue colored areas were dissected from the hearts and the EB content was determined by extraction in formamide as described previously. ${ }^{12}$ The PVC count was the total number occurring in the first 3 minutes of MCE (PVCs diminished as the contrast effect diminished and rarely occurred after 3 minutes).

After confirming that the petechiae and EB leakage appear to be separate effects, which might be due to different mechanisms, two experiments were designed to test the hypothesis that the EB leakage was a physiological response. The first experiment was designed to compare the relative magnitudes of the measured endpoints for identical exposures but with pretreatment with isoproterenol or propranolol. The second experiment was designed to follow the time course of the capillary leakage and compared the endpoints for identical exposures with and without isoproterenol pretreatment, for rats having EB injected before commencing MCE, immediately after, $10 \mathrm{~min}$ utes after, or 20 minutes after the cessation of MCE. Rats were randomly selected for placement into 12 groups according to the treatment medications and the time points for leakingtime-course experiments, as listed in Tables I and II. Data are presented as the mean and standard error of at least four results, with Student's $t$-test used to assess the significance $(\mathrm{P}<$ 0.05) of differences between group means.

\section{Results}

In the previous study, the incidence of petechiae and Evans blue leakage did not appear to be strongly correlated, and this impression was continued in this study. Figure 1 shows a portion of a heart from a rat (this study) injected with Evans blue and $0.5 \mathrm{ml} / \mathrm{kg}$ Optison ${ }^{\circledR}$, and scanned at $0 \mathrm{~dB}$, which illustrates the apparent separation of red petechiae and Evan blue colored regions. For this exposure condition, a total of 19 results for petechiae and Evans blue colored area were available from the two studies, and these results are shown in Figure 2. The linear regression line plotted in Figure 2 has a correlation coefficient $\mathrm{r}^{2}=0.21$, which confirms the poor association between the two effects. This finding led to the hypothesis that the petechiae might be due to the mechanical rupture

\section{TABLE I}

Study Groups and Results for the Vasoactive Drug Experiment

\begin{tabular}{lcccccrr}
\hline Drug & $\begin{array}{c}\text { Heart Rate } \\
\text { B:A bpm }\end{array}$ & Contrast & $\mathrm{n}^{*}$ & $\begin{array}{c}\text { PVC } \\
\text { count }\end{array}$ & $\begin{array}{c}\text { Petechiae } \\
\text { count }\end{array}$ & $\begin{array}{c}\text { EB area } \\
\%\end{array}$ & $\begin{array}{c}\text { EB content } \\
\mu \mathrm{g} / \mathrm{g}\end{array}$ \\
\hline Saline & $238(3.4): 237(3.4)$ & - & 4 & $0(0)$ & $0.6(0.4)$ & $0(0)$ & $6.0(2.4)$ \\
& & + & 8 & $18.1(5.0)$ & $204(26.4)$ & $47.4(2.8)$ & $14.7(1.8)$ \\
Isoproterenol & $246(2.7): 383(6.5)$ & - & 5 & $0(0)$ & $0.4(0.2)$ & $0(0)$ & $8.0(1.4)$ \\
& & + & 6 & $22.5(5.1)$ & $199(26.3)$ & $60.0(5.4)$ & $17.5(6.6)$ \\
Propranolol & $242(3.3): 242(2.8)$ & - & 5 & $0.4(0.4)$ & $0(0)$ & $1.3(1.3)$ & $7.9(2.8)$ \\
& & + & 5 & $18.8(6.9)$ & $236(23.0)$ & $54.7(4.2)$ & $22.5(6.0)$ \\
\hline
\end{tabular}

Results are presented as the mean and standard error in parenthesis for the listed $\mathrm{n}$ values, except as noted for the Evans blue content measurements. The minus (-) contrast conditions are essentially shams, while plus (+) contrast conditions are MCE. The heart rate is provided before and after (B:A) administration of the drug.

${ }^{*}$ For EB content, $\mathrm{n}=4$. 


\section{TABLE II}

Study Groups and Results for the Time Course Experiment Without and With Isoproterenol Pretreatment

\begin{tabular}{|c|c|c|c|c|c|c|}
\hline $\begin{array}{l}\text { Time of EB } \\
\text { Injection }\end{array}$ & Isoproterenol & $\mathrm{n}$ & $\begin{array}{l}\text { PVC } \\
\text { count }\end{array}$ & $\begin{array}{l}\text { Petechiae } \\
\text { count }\end{array}$ & $\begin{array}{c}\text { EB area } \\
\%\end{array}$ & $\begin{array}{c}\text { EB content } \\
\mu \mathrm{g} / \mathrm{g}\end{array}$ \\
\hline \multirow{2}{*}{ Sham } & - & 4 & $0(0)$ & $0.6(0.4)$ & $0(0)$ & $6.0(2.4)$ \\
\hline & + & 5 & $0(0)$ & $0.4(0.2)$ & $0(0)$ & $8.0(1.4)$ \\
\hline \multirow[t]{2}{*}{ Before } & - & 8 & $18.1(5.0)$ & $204(26.4)$ & $47.4(2.8)$ & $14.7(1.8)$ \\
\hline & + & 6 & $22.5(5.1)$ & $199(26.3)$ & $60.0(5.4)$ & $17.5(6.6)$ \\
\hline \multirow[t]{2}{*}{ Immediately after } & - & 6 & $12.8(1.5)$ & $254(40.8)$ & $34.5(8.2)$ & $13.2(2.5)$ \\
\hline & + & 6 & $21.5(5.8)$ & $265(31.4)$ & $35.6(8.6)$ & $15.3(3.1)$ \\
\hline \multirow[t]{2}{*}{10 min after } & - & 6 & $13.6(3.4)$ & $201(36.4)$ & $20.5(6.1)$ & $10.9(3.3)$ \\
\hline & + & 6 & $14.3(3.5)$ & $234(26.6)$ & $24.2(7.8)$ & $10.1(2.5)$ \\
\hline \multirow[t]{2}{*}{20 min after } & - & 7 & $15.9(4.0)$ & $220(19.4)$ & $3.5(1.5)$ & $6.8(0.6)$ \\
\hline & + & 4 & $9.0(1.7)$ & $226(28.9)$ & $2.6(1.6)$ & $6.7(1.5)$ \\
\hline
\end{tabular}

Results are presented as the mean and standard error in parenthesis for the listed n values. The "Sham" and "Before" conditions are identical to the corresponding groups in Table I.

of capillaries by acoustic cavitation microbubbles, while the capillary leakage of Evans blue dye might be due to a physiological response to released vasoactive substances (see the Introduction).

The results of the first experiment testing response modification by vasoactive drugs are detailed in Table I. The PVC, petechiae, and EB area effects for the identical MCE with different drugs were all significantly different from the respective shams. The PVC effect was highly variable for MCE, with a range of 2-48
PVCs. Most of the premature beats seen on the ECG traces appeared to be ventricular in origin (i.e., PVCs), but four rats had a majority of supraventricular premature beats. For these rats, the image plane indicated by the bluecolored area was relatively high on the heart and included the atria. The EB content results included fewer repetitions than the other endpoints (see Table I), and were statistically significant only relative to pooled shams. Results for EB-colored area are plotted in Figure 3. The isoproterenol result with MCE is slightly

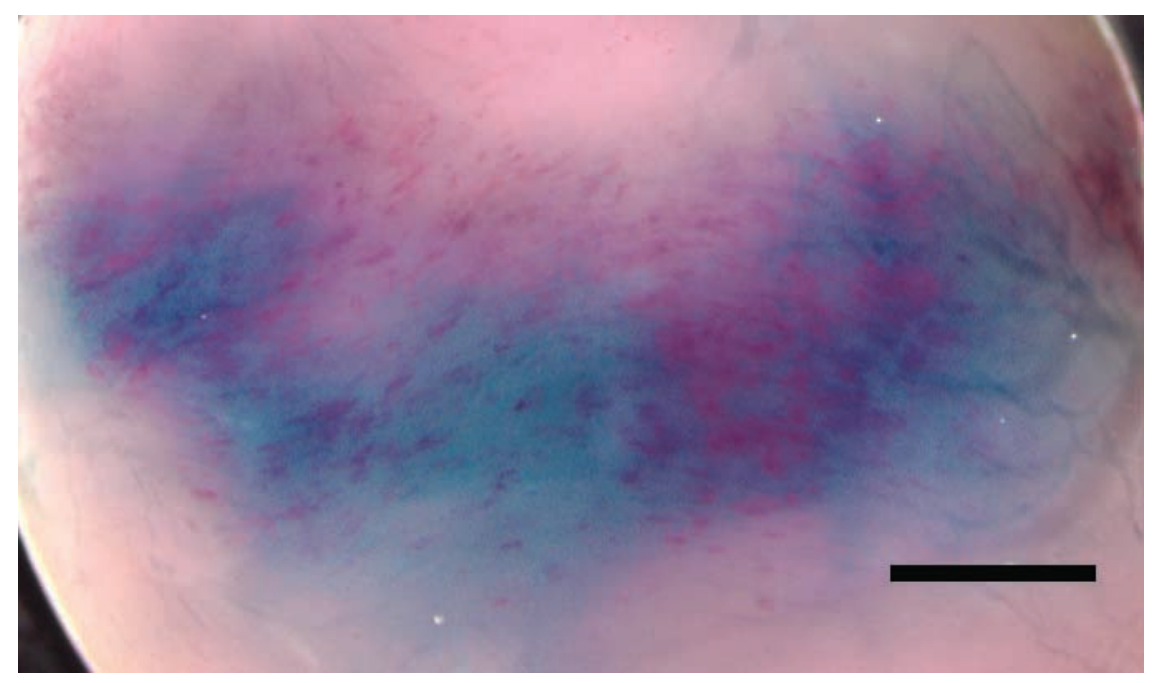

Figure 1. The anterior scanned region of an MCE heart from a rat injected with Evans blue and $0.5 \mathrm{ml} / \mathrm{kg}$ Optison $\AA$. Although the blue areas and the petechiae overlap in many places, there is an apparent separation of the effects in other regions: some red petechiae appear without being accompanied by Evan blue leakage, and some Evans blue colored regions have few petechiae. Scale bar: $2 \mathrm{~mm}$. 


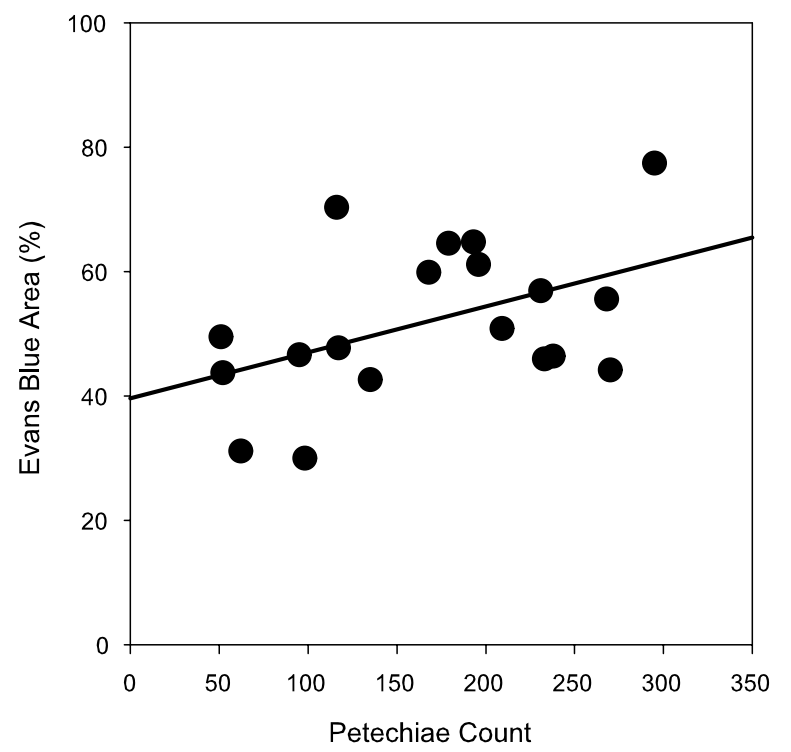

Figure 2. A total of 19 results (see text) for petechiae counts and Evans blue colored areas are displayed as a scatter plot. All the rats were injected with Evans blue and $0.5 \mathrm{ml} / \mathrm{kg}$ Optison $\AA$, and scanned at $0 \mathrm{~dB}$. The line plotted with the data presents a linear regression on this data, which has a correlation coefficient $r^{2}=0.21$.

but significantly $(\mathrm{P}<0.05)$ elevated above the saline result with $\mathrm{MCE}$, which is contrary to the initial hypothesis. This result may be related to the increased heart rate with isoproterenol pretreatment. There were no significant differences $(\mathrm{P}>0.05)$ between any of the other MCE results. This outcome, particularly the lack of a significant difference $(P=0.47)$ between the isoproterenol and propranolol results, indicate that the EB capillary leakage is not modified in support of the hypothesis by the pretreatment with vasoactive drugs.

The results of the second experiment, which followed the time course of EB leakage for rats without or with isoproterenol pretreatment, are detailed in Table II. The decrease in EB leakage was clearly visible when comparing EB injection before to 20 minutes after MCE as shown in Figure 4. Results for petechiae and EB area are plotted in Figure 5 for the various times of EB injection. The EB area decreased from the significantly increased mean values for injection before $(\mathrm{P}<0.001), 0$ minutes after $(\mathrm{P}<0.01)$ and 10 minutes after $(\mathrm{P}<0.05) \mathrm{MCE}$, relative to shams, to essentially the sham value at $20 \mathrm{~min}$ utes (no significant difference, $\mathrm{P}>0.05$ ). The EB content measurements were statistically significant only for injection of EB before MCE.

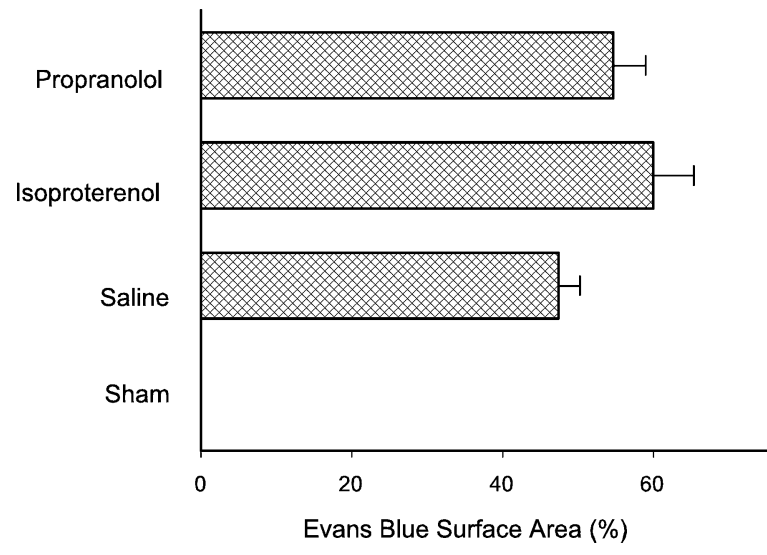

Figure 3. Results for EB-colored area for MCE with saline, and for pretreatment with isoproterenol or propranolol. The sham result (essentially zero) is a pooled value for echocardiography without contrast agent, followed by contrast agent injection.

These trends appeared to be identical without or with isoproterenol pretreatment (nonsignificant differences). These results indicate that the EB leakage diminished within 20 minutes and that this trend was not accelerated by isoproterenol pretreatment. The numbers of petechiae, which would not be expected to change with the time of EB injection, remained constant (nonsignificant differences) for all delay times, with or without isoproterenol. Of course, the time course of red cell extravasation at the petechiae sites could not be determined, but it probably follows a time course similar to the EB capillary leakage.

\section{Discussion}

In this research, rats were injected with an ultrasound contrast agent at a relatively high dosage and examined by high MI echocardiography. For injection of the agent after echocardiography, i.e., sham MCE, no effects were found. For injection of the agent before echocardiography, i.e., MCE, significant incidence of PVCs, petechiae, EB content in myocardial tissue, and EB-colored areas were found. The petechiae counts were not well correlated with the EB-colored areas found on the surface of MCE hearts. This confirms previous findings. ${ }^{12} \mathrm{Un}$ der the hypothesis that the EB leakage might be a physiological response to injury, vasoactive drugs were used in an attempt to modify the leakage, and the time course of the leakage was followed after cessation of MCE. The vasoactive drugs isoproterenol and propranolol 

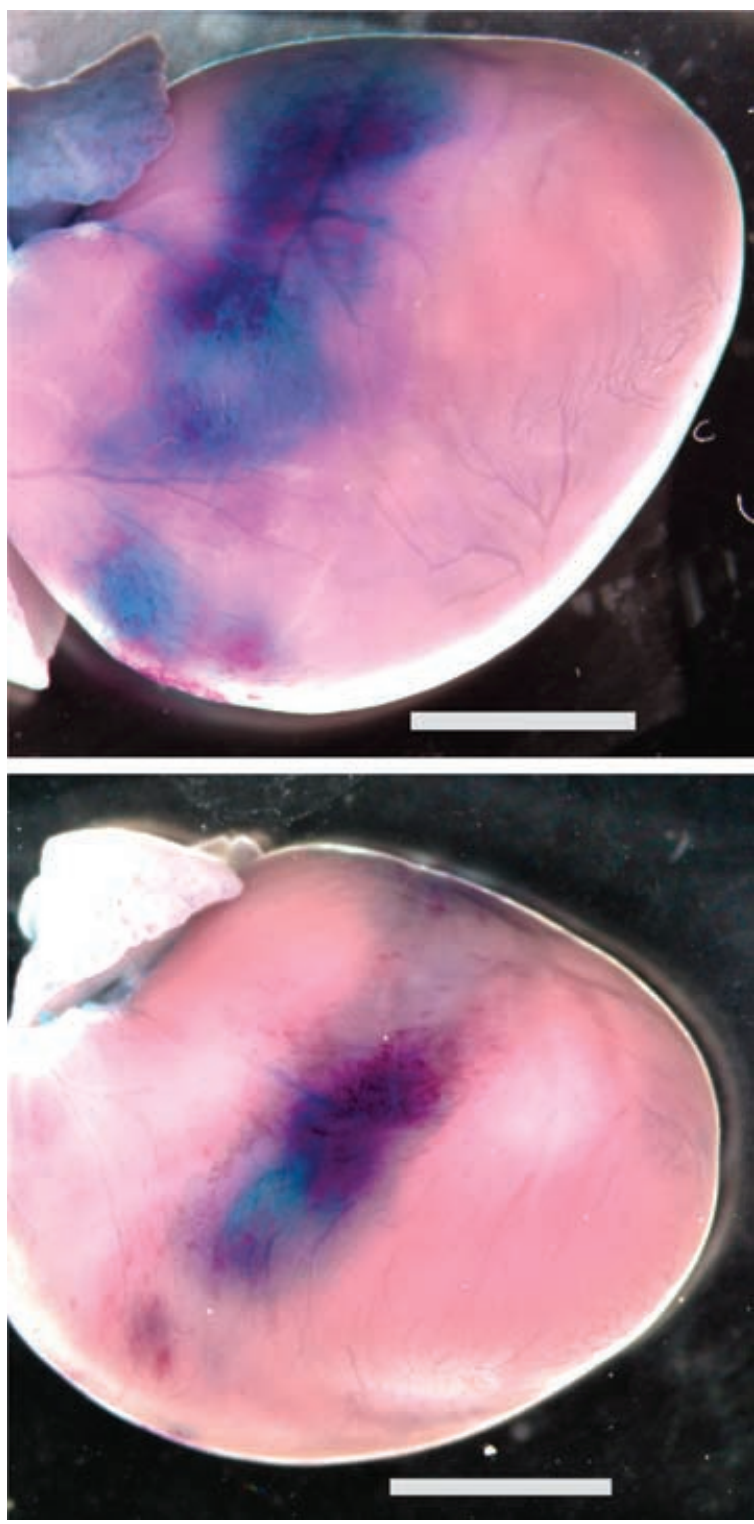

Figure 4. Photographs of rat hearts with Evans blue injection before MCE (upper) and 20 minutes after MCE (lower). The microvascular perturbation is similar, as evidenced by the similar extent of petechiae, but the blue leakage area has diminished after the 20-minute delay. Scale bar: $5 \mathrm{~mm}$.

failed to significantly modify the EB leakage in a manner consistent with the hypothesis. The small increase in EB area for MCE with isoproterenol, which was contrary to the hypothesis, may be related to the inotropic and heart-rate effects of this drug. Furthermore, the EB leakage diminished to sham levels for a 20-minute delay in the injection of $\mathrm{EB}$, and isoproterenol did not accelerate this rate of decrease. These

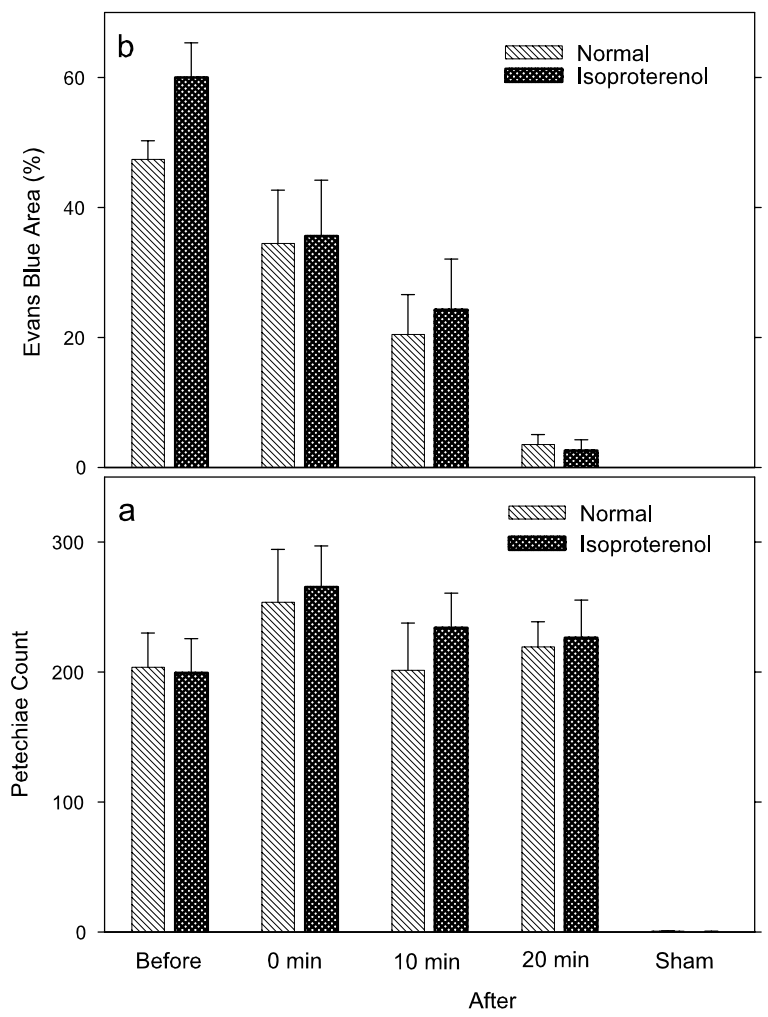

Figure 5. Results for petechiae (a) and Evans blue area (b) with different times of Evans blue injection. The numbers of petechiae, which would not be expected to change with the time of Evans blue injection, remained constant (no significant differences, $P>0.05$ ) for all delay times, with or without isoproterenol. In contrast, the Evans blue leakage steadily decreased to essentially the sham value at 20 minutes (no significant difference, $P>0.05$ ).

results do not support the hypothesis of a physiological mechanism for the EB leakage.

If this finding means that the petechiae and EB leakage were both due to a mechanical effect of acoustic cavitation activity on the capillaries, then the reason for the lack of correlation between the two effects remains unexplained. One possibility is that variations in the position and timing of the imaging frames lead to variations in the relative levels of petechiae and EB leakage in different individual rats. While both effects would be significant, they might not be well correlated. In addition, is seems likely that the visible petechiae reside primarily in the epicardium, but the EB leakage could occur in the interior of the myocardium with diffusion toward the surface where it becomes visible as uniform blue regions. Evans blue leaking out with the red cells in the surface petechiae 
might not remain closely associated with the localized red cells, and thus not lend the petechiae a blue coloration. The apparent attribution of both effects to mechanical permeabilization of capillaries, which might be quickly reversed or repaired, is less suggestive of long-term risk in MCE than a physiological inflammationlike cascade effect with potentially serious consequences.

\section{Study Limitations}

The findings reported here are limited by the highly variable nature of the results from the small animals. Both the precise location of the scan plane on the small hearts, and the exact timing of the imaging frames $(33 \mathrm{~ms}$ increments, with an approximate $250 \mathrm{~ms}$ duration heart rate) contribute to the variability. A relatively high dose of Optison was used for sensitivity, which limits the relevance to normal clinical doses. In addition, there was no positive control test (e.g., dosages employed were taken from rat skin studies), which limits the assurance of the negative results. A small rapid effect on capillary permeability due to released vasoactive substances cannot be ruled out, and the possible longer term (hours to days) inflammatory response to injury was not studied.

\section{Conclusions}

Within the limits noted above, several conclusions can be derived from this study. PVCs, capillary rupture, and leakage result from MCE with high MI and high contrast doses, but not from echocardiography or contrast injection alone. The petechiae and EB leakage endpoints were not strongly correlated. However, the EB leakage diminished within 20 minutes, and modulation by vasoactive drugs did not support the hypothesis of a separate physiological mechanism for the EB leakage. The petechiae and EB leakage are therefore likely due to similar physical processes related to acoustic cavitation, with the explanation of their minimal correlation remaining uncertain.

Acknowledgment: We thank Dr. A. R. Williams, Swansea UK, for helpful discussions and advice on this research.

\section{References}

1. Mulvagh SL, DeMaria AN, Feinstein SB, et al: Contrast echocardiography: Current and future applications. J Am Soc Echocard 2000;13:331-342.
2. Nyborg WL, Carson PL, Carstensen EL, et al: Exposure Criteria for Medical Diagnostic Ultrasound: II. Criteria Based on All Known Mechanisms. Report No. 140, National Council on Radiation Protection and Measurements, Bethesda, MD, 2002.

3. AIUM: Mechanical bioeffects from diagnostic ultrasound: AIUM consensus statements. J Ultrasound Med 2000;19:67-168.

4. Miller DL: The safety of ultrasound contrast agents. In ter Haar G, Duck F (eds): The Safe Use of Ultrasound in Medical Diagnosis. The British Medical Ultrasound Society/The British Institute of Radiology. London, 2000, pp. 72-85.

5. Fowlkes JB, Miller DL: In vivo measurements of bioeffects. In Goldberg BB, Raichlen JS, Forsberg F (eds): Ultrasound Contrast Agents: Basics Principles and Clinical Applications. London, Martin Dunitz Ltd., 2001, Ch. 13.

6. Skyba DM, Camarano G, Goodman NC, et al: Hemodynamic characteristics, myocardial kinetics and microvascular rheology of FS-069, a second-generation echocardiographic contrast agent capable of producing myocardial opacification from a venous injection. J Am Coll Cardiol 1996;28:1292-1300.

7. Miller DL, Quddus J: Diagnostic ultrasound activation of contrast agent gas bodies induces capillary rupture in mice. Proc Nat Acad Sci USA 2000;97:10179-10184.

8. AIUM: Statement on bioeffects of diagnostic ultrasound with gas body contrast agents. Sound Waves 2002;19:3.

9] van der.Wouw PA, Brauns AC, Bailey SE, et al: Premature ventricular contractions during triggered imaging with ultrasound contrast. J Am Soc Echocardiogr 2000;13:288-294.

10. Ay T, Havauz X, Van Camp G, et al: Destruction of contrast microbubbles by ultrasound effects on myocardial function, coronary perfusion pressure and microvascular integrity. Circulation 2001;104:461-466.

11. Chen S, Kroll MH, Shohet RV, et al: Bioeffects of myocardial contrast microbubble destruction by echocardiography. Echocardiography 2002;19:495-500.

12. Li P, Cao LQ, Dou CY, et al. Impact of myocardial contrast echocardiography on vascular permeability: An in vivo dose response study of delivery mode, ultrasound power and contrast dose. Ultrasound Med Biol, 2003;29:1341-1349.

13. Zachary JF, Hartleben SA, Frizzell LA, et al: Arrhythmias in rat hearts exposed to pulsed ultrasound after intravenous injection of a contrast agent. J Ultrasound Med 2002;21:1347-1356.

14. Porter TR, Everbach C, Kricsfeld D, et al: Myocardial cavitational activity during continuous infusion and bolus intravenous injections of perfluorocarboncontaining microbubbles. $J \mathrm{Am}$ Soc Echocardiogr 2001;14:618-625.

15. Brayman AA, Strickler PL, Luan H, et al: Hemolysis of $40 \%$ hematocrit, Albunex ${ }^{\circledR}$ supplemented human erythrocytes by pulsed ultrasound: Frequency, acoustic pressure and pulse length dependence. Ultrasound Med \& Biol 1997;23:1237-1250.

16. Miller DL, Gies RA: Enhancement of ultrasonicallyinduced hemolysis by perfluorocarbon-based compared to air-based echo-contrast agents. Ultrasound Med \& Biol 1998;24:285-292.

17. Everbach EC, Makin IR, Azadniv M, et al: Effect of acoustic cavitation on platelets in the presence of an echo-contrast agent. Ultrasound Med \& Biol 1998;24:129-136. 
18. Dayton PA, Chomas JE, Lum A, et al: Optical and acoustical dynamics of microbubble contrast agents inside neutrophils. Biophys J 2001;80:15471556.

19. Miller DL, Quddus J: Lysis and sonoporation of epidermoid and phagocytic monolayer cells by diagnostic ultrasound activation of contrast-agent gas bodies. $U l$ trasound Med \& Bio 2001;27:1107-1113.

20. Brayman AA, Lizotte LM, Miller MW: Erosion of artificial endothelia in vitro by pulsed ultrasound: Acoustic pressure frequency, membrane orientation and mi- crobubble contrast agent dependence. Ultrasound Med \& Biol 1999;25:1305-1320.

21. Marone G, Crescenzo G, Adt M, et al: Immunological characterization and functional importance of human heart mast cells. Immunopharmacology 1995;31:1-18.

22. Chakraborti T, Mandal A, Mandal M, et al: Complement activation in heart diseases: Role of oxidants. Cellular Signaling 2000;12:607-617.

23. Ding Z, Jiang M, Li S, et al: Vascular barrierenhancing effect of an endogenous $\beta$-adrenergic agonist. Inflammation 1995;19:1-8. 